\title{
What Factors Lead to Racial Disparities in Outcomes After Total Knee Arthroplasty?
}

\author{
Daniel A. Hu ${ }^{1}$. James B. Hu $\cdot$ Ariel Lee ${ }^{2} \cdot$ William J. Rubenstein ${ }^{3} \cdot$ Kevin M. Hwang ${ }^{3} \cdot$ Said A. Ibrahim ${ }^{4}$. \\ Alfred C. Kuo ${ }^{3,5}$
}

Received: 1 September 2021 / Revised: 1 September 2021 / Accepted: 1 October 2021 / Published online: 12 October 2021

This is a U.S. government work and not under copyright protection in the U.S.; foreign copyright protection may apply 2021

\begin{abstract}
Total knee arthroplasty (TKA) is one of the most commonly performed, major elective surgeries in the USA. African American TKA patients on average experience worse clinical outcomes than whites, including lower improvements in patientreported outcomes and higher rates of complications, hospital readmissions, and reoperations. The mechanisms leading to these racial health disparities are unclear, but likely involve patient, provider, healthcare system, and societal factors. Lower physical and mental health at baseline, lower social support, provider bias, lower rates of health insurance coverage, higher utilization of lower quality hospitals, and systemic racism may contribute to the inferior outcomes that African Americans experience. Limited evidence suggests that improving the quality of surgical care can offset these factors and lead to a reduction in outcome disparities.
\end{abstract}

Keywords Total knee arthroplasty $\cdot$ Clinical outcomes $\cdot$ Racial health disparity $\cdot$ Readmission

\section{Introduction}

Total knee arthroplasty (TKA) is one of the most common major surgeries performed in the USA and accounts for a large proportion of Medicare surgical expenditures. Although most patients experience improved symptoms and function after surgery, patients from racial and ethnic minorities often experience worse outcomes after surgery than white patients. Compared to whites, African American TKA patients have been reported to experience higher

Daniel A. Hu and James B. Hu contributed equally to this work.

Alfred C. Kuo

alfred.kuo@ucsf.edu

1 Northwestern University Feinberg School of Medicine, Chicago, IL, USA

2 Irvine School of Medicine, University of California, Irvine, CA, USA

3 Department of Orthopaedic Surgery, University of California, San Francisco, CA, USA

4 Department of Healthcare Policy and Research, Weill Cornell Medicine, New York City, NY, USA

5 Orthopedic Surgery Section, San Francisco Veterans Affairs Health Care System, San Francisco, CA, USA rates of complications, readmissions, revision surgery, and mortality as well as smaller improvements in patientreported outcome measures (PROMs) [1-5]. These results are found in a wide range of health care systems across the USA. Black TKA patients of Kaiser Permanente, one of the largest private, nonprofit healthcare plans in the USA, have higher rates of emergency department visits, readmissions, and aseptic revision surgery than white patients [6]. In a study of TKAs performed in the State of Pennsylvania, Blum et al. also demonstrated that black patients had higher rates of revision surgery [7]. Outcome disparities exist for patients of the Veterans Health Administration (VHA), even though the VHA is an equal-access system that provides care to veterans regardless of race, ethnicity, income, or other socioeconomic factors. Ibrahim et al. found that black VHA TKA patients experienced higher complication rates than whites [8]. More recently, we have found that black VHA TKA patients have lower improvements in PROMs and higher rates of revision surgery $[9,10]$.

There is no consensus as to why these disparities exist, and they are unlikely to arise from a single cause. The goal of this review is to describe the interrelated patient, provider, healthcare system, and societal factors that likely contribute to the poorer outcomes of black patients compared to whites. 
An understanding of the causes of disparities is required to guide actions to reduce unequal outcomes.

\section{Patient Factors}

Multiple patient-specific factors may contribute to racial disparities in clinical outcomes following TKA. The poorer health of the black population compared to whites is likely to be a key contributor. According to 2015 data from the Behavioral Risk Factor Surveillance System, African Americans have higher rates of medical conditions such as obesity, hypertension, diabetes mellitus, and history of stroke than whites across all age groups [11]. Medical comorbidities are associated with poorer surgical outcomes and increased complication rates following TKA. For example, diabetes mellitus and super obesity are independent risk factors for surgical site infection after upper and lower extremity arthroplasty [12]. In a study of the National Inpatient Sample, Hustedt et al. demonstrated that patients with more comorbidities had higher rates of postoperative complications following total hip and knee arthroplasties [13]. Congestive heart failure, valvular heart disease, and chronic obstructive pulmonary disease were associated with the highest risks of major complications. Elmallah et al. found in a cohort of 283 TKA patients that those with hypertension, cardiovascular disease, endocrine disease, and gastrointestinal disease had worse postoperative PROM results compared to those without these comorbidities [14].

Differences in preoperative psychologic health may also contribute to racial disparities after TKA. Adverse baseline psychological health increases the likelihood of poor outcomes following TKA. In a systematic review of 19 publications, including ten from the USA, psychological health was found to be a significant predictor of pain, function, or satisfaction after TKA in 16 studies [15]. Patients with preoperative anxiety or severe depression experience greater pain 1 year after TKA than patients without these conditions [16]. These effects can persist over time and preoperative depression is associated with lower knee PROM scores 5 years after surgery [17]. Although African Americans have a lower or equivalent incidence of mental illness compared to the general population, blacks often experience more severe psychiatric illness [18] and commonly experience higher levels of psychological distress [19]. In addition, black Americans with mood and anxiety disorders have a higher risk of experiencing persistent symptoms compared to whites [20]. Finally, African Americans are less likely to utilize mental health services than whites [21], which may be due to lack of health insurance, internalized stigma to seeking care for mental health issues, and/or distrust of medical providers.
Perceived poor social support can also affect mental health outcomes [22] and differences in social support may also contribute to racial disparities above and beyond their direct effects on mental health. Social isolation is associated with negative physical and mental health outcomes across races [23]. In a survey of 799 patients with knee osteoarthritis (OA), African Americans were less likely to be married, reported fewer close friends, and had lower Medical Outcomes Study-Social Support Scale (MOS-SSS) scores compared to whites [24]. Similarly, in a survey of 909 male VHA patients with moderate or severe hip or knee OA, the mean MOS-SSS score for black patients was significantly lower than for white patients [25]. The MOSS-SSS consists of four functional support scales (tangible, emotional/informational, affectionate support, and positive social interaction) [26]. Less tangible support has in turn been associated with worse Western Ontario McMaster function scores after TKA [27].

The socioeconomic status (SES) of the black population is another contributor to racial differences in outcomes [28]. Data from the 2019 Survey of Consumer Finances shows marked, persistent racial disparities in family wealth in the USA, with white families having eight times the wealth of black families [29]. For Americans less than 65 years of age, blacks have higher rates of unmet health care needs secondary to cost, lower rates of health insurance coverage, higher rates of public health insurance, and lower rates private health insurance compared to whites [30, 31]. Race, SES, and insurance status interact to affect outcomes after surgery. Multivariate analysis of state administrative data shows that black race, higher comorbidity burden, lower income, and public payer status (Medicare and Medicaid) are all associated with significantly higher rates of readmission after TKA [32]. Racial disparities in health insurance coverage will be further examined in the discussion on healthcare system effects.

\section{Provider and Healthcare System Factors}

Provider bias is hypothesized to be another contributor to racial disparities after TKA. Bias is defined as a prejudice for or against a person, thing, or idea. Biases range from overt prejudices and stereotypes to subtle attitudes that can affect perception, behaviors, and decision-making. Implicit biases are unconscious attitudes and associations that are automatically triggered when thinking about specific social groups [33]. Although most providers strive to avoid conscious biases while treating patients, it is harder to avoid unconscious, implicit biases. The implicit association test (IAT), a validated tool measuring the strength of association between concepts, has been widely used to measure implicit bias among providers [34]. The IAT pairs different photos of black and white people with "pleasant" or "unpleasant" 
words. The faster and more accurately the participant responds to the pairings, the stronger the association. For instance, a person with an implicit pro-white bias will pair a photo of a smiling white person with "pleasant" words such as beautiful and happy more quickly and accurately than a photo of a smiling black person. Multiple studies have found evidence of implicit racial bias among healthcare providers as well as an association between implicit racial bias and inferior communication between patients and providers [34, 35]. Although the literature is clear that racial implicit bias impacts patient-provider interactions, there is less clarity regarding the impact on clinical outcomes [36]. There is little data regarding bias and a surgeon's decision to offer treatment in real-world settings. For example, racial disparities in outcomes may arise in part if surgeons are more willing to offer TKA to high-risk African American patients with multiple comorbidities than to similar white patients. Future studies must examine the relationships between provider bias and patient outcomes in real-life scenarios rather than in standardized patient cases or theoretical vignettes.

Provider and healthcare system quality are also likely key contributors to racial disparities in TKA outcomes. Disparities in healthcare outcomes between minority populations and whites are generally not due to worse quality of care within the same hospital. In a study examining inpatient discharge data across thirteen states and comparing riskadjusted quality indicators by race and ethnicity, only a small subset of hospitals was found to provide systematically lower quality care to minority groups [37]. Instead, African American patients tend to undergo surgery at lower-quality hospitals than whites. Analysis of Medicare data from 2005 to 2008 demonstrated that while African American patients lived closer to higher-quality hospitals (assessed with composite measures factoring in risk-adjusted morbidity and outcomes) than white patients, they were more likely than whites to undergo major surgery (coronary artery bypass, abdominal aortic aneurysm repair, and lung cancer resection) at lower-quality hospitals [38]. Use of lower-quality hospitals was strongly associated with higher degrees of racial residential segregation. Similarly, analysis of records of elderly Medicare beneficiaries who received TKAs from 2002 to 2005 showed that African American patients were more likely than their white counterparts to be admitted to hospitals with higher risk-adjusted rates of postoperative complications or mortality [39]. Data on hospital TKA volume also suggests that black patients often undergo surgery in lower-quality institutions. Total hip and knee arthroplasty volume correlates with composite hospital quality scores [40] and African Americans are less likely to undergo TKA in high-volume hospitals than white Americans [4].

Disparities in health insurance coverage may also contribute to the higher utilization of lower-quality hospitals by African American patients. Uninsured and underinsured patients often receive care at safety-net hospitals [41], which frequently demonstrate poor performance on quality measures such as readmissions [42]. In 2014, 20.7\% of black nonelderly adults were uninsured compared to $11.7 \%$ of whites [31]. In addition, 26.4\% of black patients and $13.9 \%$ of white patients had public health insurance. Medicaid payer status has been found to be an important factor in predicting total joint arthroplasty outcomes. For example, in a systematic review by Lakomkin et al., seven analyses identified a significant association between Medicaid coverage and short-term readmissions, and two analyses demonstrated a relationship between prolonged length of stay and Medicaid insurance status [43].

\section{Societal Factors}

Multiple governmental and medical organizations in the USA, including the National Institutes of Health, have concluded that structural racism contributes to racial health disparities [44]. Systemic racism is defined as policies and practices in institutions, including those in health care, housing, employment, and education, that lead to the exclusion or promotion of specific groups [45, 46]. It can be divided into two categories, institutional and structural racism. Institutional racism specifically occurs within and between institutions and consists of discriminatory treatment and differences in opportunities based on race, perpetuated by institutions such as schools and hospitals. One example is the legalized racial segregation of medical and other facilities by Jim Crow laws. Structural racism occurs within a society and encompasses the history of a particular nation, such as culture which normalizes and legitimizes racism, and the institutions (housing, education, employment, earnings, and health care) which reinforce and perpetuate racism. Importantly, structural racism does not comprise the actions or intent of specific individuals, but rather exists on a macro-scale [47].

There are as of yet few papers on the effects of systemic racism in orthopedics, much less the effects of systemic racism on TKA outcomes. Structural racism can affect health through multiple pathways, including racial residential segregation. Discriminatory practices present today in more subtle ways than in previous decades, and overt methods by which racial segregation was historically achieved, such Jim Crow laws, are rare or absent. Current methods are less conspicuous, such as the use of "racial steering" for segregating neighborhoods [47]. In this practice, prospective home buyers are guided by real estate brokers toward or away from certain neighborhoods based on the buyers' race. Racial residential segregation has been hypothesized to influence health outcomes by affecting health system infrastructure, including availability of 
health care services and facilities, and by affecting neighborhood context, including the social, physical, economic, and environmental factors that influence well-being [48, 49]. The concentration of minorities into less desirable and lower SES neighborhoods correlates to exposure to pollutants, decreased longevity, increased risk of chronic disease, and higher crime rates [46, 47]. Societal conditions therefore contribute to the patient, provider, and healthcare system factors that drive disparities in outcomes.

\section{Conclusion}

African American patients are more likely to experience worse outcomes after TKA than white patients. The reasons for this are multifactorial and complex, and likely include disparities in physical and mental health, unequal access to quality healthcare, and structural inequities in society. Just as there is no single, simple reason for these unequal outcomes, there is no single, simple solution. The findings of Aseltine et al. offer some hope [50]. Using claims data from the State of Connecticut, they estimated the rates of 30-day admissions after total hip and knee arthroplasty from 2005 to 2015 . As with previous studies, they found that African Americans had higher readmission rates than whites at the beginning of the study period. By 2015 , readmission rates had declined for all races, and the difference between black and white patients had narrowed. Although the authors were unable to identify the reasons for this reduction in readmission disparity, there is evidence suggesting that improving the quality of surgical care may reduce health care disparities. In a single-institution study of postoperative length of stay after colorectal surgery, racial disparities in lengths of stay were eliminated after implementation of an enhanced recovery after surgery pathway [51]. Further research is required to fully understand the processes that lead to disparities after TKA and to design programs to reduce these disparities.

Data Availability Not applicable.

Code Availability Not applicable.

\section{Declarations}

Ethics Approval Not applicable.

Consent to Participate Not applicable.

Consent for Publication Not applicable.

Conflict of Interest The authors declare no competing interests.
Open Access This article is licensed under a Creative Commons Attribution 4.0 International License, which permits use, sharing, adaptation, distribution and reproduction in any medium or format, as long as you give appropriate credit to the original author(s) and the source, provide a link to the Creative Commons licence, and indicate if changes were made. The images or other third party material in this article are included in the article's Creative Commons licence, unless indicated otherwise in a credit line to the material. If material is not included in the article's Creative Commons licence and your intended use is not permitted by statutory regulation or exceeds the permitted use, you will need to obtain permission directly from the copyright holder. To view a copy of this licence, visit http://creativecommons.org/licenses/by/4.0/.

\section{References}

1. Shahid H, Singh JA. Racial/ethnic disparity in rates and outcomes of total joint arthroplasty. Curr Rheumatol Rep. 2016;18(4):20. https://doi.org/10.1007/s11926-016-0570-3.

2. Mehta B, Ho K, Bido J, Memtsoudis SG, Parks ML, Russell L, Goodman SM, Ibrahim S. Bilateral vs unilateral total knee arthroplasty: racial variation in utilization and in-hospital major complication rates. J Arthroplasty. 2020;S08835403(20):31156-66. https://doi.org/10.1016/j.arth.2020.10.057.

3. Bass AR, McHugh K, Fields K, Goto R, Parks ML, Goodman SM. Higher total knee arthroplasty revision rates among United States Blacks than Whites: a systematic literature review and meta-analysis. J Bone Joint Surg Am. 2016;98(24):2103-8. https://doi.org/10.2106/JBJS.15.00976.

4. Zhang W, Lyman S, Boutin-Foster C, Parks ML, Pan TJ, Lan A, Ma Y. Racial and ethnic disparities in utilization rate, hospital volume, and perioperative outcomes after total knee arthroplasty. J Bone Joint Surg Am. 2016;98(15):1243-52. https:// doi.org/10.2106/JBJS.15.01009.

5. Goodman SM, Parks ML, McHugh K, Fields K, Smethurst R, Figgie MP, Bass AR. Disparities in outcomes for African Americans and Whites undergoing total knee arthroplasty: a systematic literature review. J Rheumatol. 2016;43(4):765-70. https://doi.org/10.3899/jrheum.150950.

6. Hinman AD, Chan PH, Prentice HA, Paxton EW, Okike KM, Navarro RA. The association of race/ethnicity and total knee arthroplasty outcomes in a universally insured population. $\mathrm{J}$ Arthroplasty. 2020;35(6):1474-9. https://doi.org/10.1016/j. arth.2020.02.002.

7. Blum MA, Singh JA, Lee G-C, Richardson D, Chen W, Ibrahim SA. Patient race and surgical outcomes after total knee arthroplasty: an analysis of a large regional database. Arthritis Care Res. 2013;65(3):414-20. https://doi.org/10.1002/acr.21834.

8. Ibrahim SA, Stone RA, Han X, Cohen P, Fine MJ, Henderson WG, Khuri SF, Kwoh CK. Racial/ethnic differences in surgical outcomes in veterans following knee or hip arthroplasty. Arthritis Rheum. 2005;52(10):3143-51. https://doi.org/10.1002/art. 21304.

9. Rubenstein WJ, Harris AHS, Hwang KM, Giori NJ, Kuo AC. Social determinants of health and patient-reported outcomes following total hip and knee arthroplasty in veterans. J Arthroplasty. 2020;35(9):2357-62. https://doi.org/10.1016/j.arth.2020.04.095.

10. Bendich I, Zhang N, Barry JJ, Ward DT, Whooley MA, Kuo AC. Antibiotic-laden bone cement use and revision risk after primary total knee arthroplasty in U.S. veterans. JBJS. 2020;102(22):1939-47. https://doi.org/10.2106/JBJS.20.00102.

11. Centers for Disease Control and Prevention: African American Health. Creating equal opportunities for health. www.cdc.gov/ vitalsigns/aahealth/index.html. Accessed 6 Feb 2021. 
12. Everhart JS, Altneu E, Calhoun JH. Medical comorbidities are independent preoperative risk factors for surgical infection after total joint arthroplasty. Clin Orthopaed Relat Res. 2013;471(10):3112-9. https://doi.org/10.1007/ s11999-013-2923-9.

13. Hustedt JW, Goltzer O, Bohl DD, Fraser JF, Lara NJ, Spangehl MJ. Calculating the cost and risk of comorbidities in total joint arthroplasty in the United States. J Arthroplasty. 2017;32(2):355361.e1. https://doi.org/10.1016/j.arth.2016.07.025.

14. Elmallah RDK, Cherian JJ, Robinson K, Harwin SF, Mont MA. The effect of comorbidities on outcomes following total knee arthroplasty. J Knee Surg. 2015;28(5):411-6. https://doi.org/10. 1055/s-0035-1549023.

15. Khatib Y, Madan A, Naylor JM, Harris IA. Do psychological factors predict poor outcome in patients undergoing TKA? A systematic review. Clin Orthop Relat Res. 2015;473(8):2630-8. https://doi.org/10.1007/s11999-015-4234-9.

16. Brander VA, Stulberg SD, Adams AD, Harden RN, Bruehl S, Stanos SP, Houle T. Predicting total knee replacement pain: a prospective, observational study. Clin Orthop Relat Res. 2003;416:27-36. https://doi.org/10.1097/01.blo.0000092983. 12414.e9.

17. Brander V, Gondek S, Martin E, Stulberg SD. Pain and depression influence outcome 5 years after knee replacement surgery. Clin Orthop Relat Res. 2007;464:21-6. https://doi.org/10.1097/BLO. 0b013e318126c032.

18. McGuire TG, Miranda J. New evidence regarding racial and ethnic disparities in mental health: policy implications. Health Aff. 2008;27(2):393-403. https://doi.org/10.1377/hlthaff.27.2.393.

19. Barnes DM, Bates LM. Do racial patterns in psychological distress shed light on the Black-White depression paradox? A systematic review. Soc Psychiatry Psychiatr Epidemiol. 2017;52(8):913-28. https://doi.org/10.1007/s00127-017-1394-9.

20. Breslau J, Kendler KS, Su M, Gaxiola-Aguilar S, Kessler RC. Lifetime risk and persistence of psychiatric disorders across ethnic groups in the United States. Psychol Med. 2005;35(3):317-27. https://doi.org/10.1017/s0033291704003514.

21. Racial/ethnic differences in mental health service use among adults I CBHSQ data. https://www.samhsa.gov/data/report/racia lethnic-differences-mental-health-service-use-among-adults. Accessed 12 Oct 2020.

22. Wang J, Mann F, Lloyd-Evans B, Ma R, Johnson S. Associations between loneliness and perceived social support and outcomes of mental health problems: a systematic review. BMC Psychiatry. 2018;18(1):156. https://doi.org/10.1186/s12888-018-1736-5.

23. Miyawaki CE. Association of social isolation and health across different racial and ethnic groups of older Americans. Ageing Soc. 2015;35(10):2201-28. https://doi.org/10.1017/S0144686X140008 90.

24. Vina ER, Cloonan YK, Ibrahim SA, Hannon MJ, Boudreau RM, Kwoh CK. Race, gender and total knee replacement consideration: the role of social support. Arthritis Care Res. 2013;65(7):110311. https://doi.org/10.1002/acr.21925.

25. Groeneveld PW, Kwoh CK, Mor MK, Appelt CJ, Geng M, Gutierrez JC, Wessel DS, Ibrahim SA. Racial differences in expectations of joint replacement surgery outcomes. Arthritis Rheum. 2008;59(5):730-7. https://doi.org/10.1002/art.23565.

26. Sherbourne CD, Stewart AL. The MOS social support survey. Soc Sci Med. 1991;32(6):705-14. https://doi.org/10.1016/02779536(91)90150-b.

27. Lopez-Olivo MA, Landon GC, Siff SJ, Edelstein D, Pak C, Kallen MA, Stanley M, Zhang H, Robinson KC, Suarez-Almazor ME. Psychosocial determinants of outcomes in knee replacement. Ann Rheum Dis. 2011;70(10):1775-81. https://doi.org/10.1136/ard. 2010.146423.
28 Williams DR. Race, socioeconomic status, and health. The added effects of racism and discrimination. Ann N Y Acad Sci. 1999;896:173-88. https://doi.org/10.1111/j.1749-6632.1999. tb08114.x.

29. Disparities in wealth by race and ethnicity in the 2019 survey of consumer finances. [accessed 23 Jan 2021]. https://www.feder alreserve.gov/econres/notes/feds-notes/disparities-in-wealth-byrace-and-ethnicity-in-the-2019-survey-of-consumer-finances20200928.htm.

30. Okoro CA, Zhao G, Fox JB, Eke PI, Greenlund KJ, Town M. Surveillance for health care access and health services use, adults aged 18-64 years - behavioral risk factor surveillance system, United States, 2014. MMWR Surveill Summ. 2017;66(7):1-42. https://doi.org/10.15585/mmwr.ss6607a1.

31. Buchmueller TC, Levinson ZM, Levy HG, Wolfe BL. Effect of the affordable care act on racial and ethnic disparities in health insurance coverage. Am J Public Health. 2016;106(8):1416-21. https://doi.org/10.2105/AJPH.2016.303155.

32. Arroyo NS, White RS, Gaber-Baylis LK, La M, Fisher AD, Samaru M. Racial/ethnic and socioeconomic disparities in total knee arthroplasty 30- and 90-day readmissions: a multipayer and multistate analysis, 2007-2014. Popul Health Manag. 2019;22(2):175-85. https://doi.org/10.1089/pop.2018.0025.

33. Payne BK, Vuletich HA, Brown-Iannuzzi JL. Historical roots of implicit bias in slavery. Proc Natl Acad Sci U S A. 2019; 116(24): 11693-11698. Published online 2019 May 28. https://doi.org/10. 1073/pnas.1818816116.

34. Maina IW, Belton TD, Ginzberg S, Singh A, Johnson TJ. A decade of studying implicit racial/ethnic bias in healthcare providers using the implicit association test. Soc Sci Med. 1982;2018(199):21929. https://doi.org/10.1016/j.socscimed.2017.05.009.

35. Dehon E, Weiss N, Jones J, Faulconer W, Hinton E, Sterling S. A systematic review of the impact of physician implicit racial bias on clinical decision making. Acad Emerg Med. 2017;24(8):895904. https://doi.org/10.1111/acem.13214.

36. Hall WJ, Chapman MV, Lee KM, Merino YM, Thomas TW, Payne BK, Eng E, Day SH, Coyne-Beasley T. Implicit racial/ ethnic bias among health care professionals and its influence on health care outcomes: a systematic review. Am J Public Health. 2015;105(12):e60-76. https://doi.org/10.2105/AJPH. 2015. 302903.

37. Gaskin DJ, Spencer CS, Richard P, Anderson GF, Powe NR, Laveist TA. Do hospitals provide lower-quality care to minorities than to whites? Health Aff (Millwood). 2008;27(2):518-27. https://doi.org/10.1377/hlthaff.27.2.518.

38. Dimick J, Ruhter J, Sarrazin MV, Birkmeyer JD. Black patients more likely than whites to undergo surgery at low-quality hospitals in segregated regions. Health Aff (Millwood). 2013;32(6):104653. https://doi.org/10.1377/hlthaff.2011.1365.

39. Cai X, Cram P, Vaughan-Sarrazin M. Are African American patients more likely to receive a total knee arthroplasty in a lowquality hospital? Clin Orthop Relat Res. 2012;470(4):1185-93. https://doi.org/10.1007/s11999-011-2032-6.

40. Hollenbeck B, Hoffman MA, Tromanhauser SG. High-volume arthroplasty centers demonstrate higher composite quality scores and enhanced value: perspective on higher-volume hospitals performing arthroplasty from 2001 to 2011. J Bone Joint Surg Am. 2020;102(5):362-7. https://doi.org/10.2106/JBJS.19.00139.

41. Institute of Medicine (US) Committee on the Changing Market, Managed Care, and the Future Viability of Safety Net Providers. In: Ein Lewin M, Altman S, editors. America's Health Care Safety Net: Intact but Endangered. Washington (DC): National Academies Press (US); 2000.

42. Joynt KE, Jha AK. Characteristics of hospitals receiving penalties under the hospital readmissions reduction program. JAMA. 2013;309(4):342-3. https://doi.org/10.1001/jama.2012.94856. 
43. Lakomkin N, Hutzler L, Bosco JAI. The relationship between Medicaid coverage and outcomes following total knee arthroplasty: a systematic review. JBJS Reviews. 2020;8(4): e0085. https://doi.org/10.2106/JBJS.RVW.19.00085.

44. National Institutes of Health; https://www.nih.gov/ending-struc tural-racism; accessed 28 Mar 2021.

45. Forms of racism. Alberta Civil Liberties Research Centre. [accessed 13 Oct 2020]. http://www.aclrc.com/forms-of-racism.

46. Bailey ZD, Krieger N, Agénor M, Graves J, Linos N, Bassett MT. Structural racism and health inequities in the USA: evidence and interventions. Lancet. 2017;389(10077):1453-63. https://doi.org/ 10.1016/S0140-6736(17)30569-X

47. Gee GC, Ford CL. Structural racism and health inequities: old issues, new directions. Du Bois Rev. 2011;8(1):115-32. https:// doi.org/10.1017/S1742058X11000130.

48. White K, Haas JS, Williams DR. Elucidating the role of place in health care disparities: the example of racial/ethnic residential segregation. Health Serv Res. 2012;47(3 Pt 2):1278-99. https:// doi.org/10.1111/j.1475-6773.2012.01410.x.

49. Chapman EN, Kaatz A, Carnes M. Physicians and implicit bias: how doctors may unwittingly perpetuate health care disparities. J
Gen Intern Med. 2013;28(11):1504-10. https://doi.org/10.1007/ s11606-013-2441-1.

50. Aseltine RH Jr, Wang W, Benthien RA, Katz M, Wagner C, Yan $\mathrm{J}$, Lewis CG. Reductions in race and ethnic disparities in hospital readmissions following total joint arthroplasty from 2005 to 2015 . J Bone Joint Surg Am. 2019;101(22):2044-50. https://doi.org/10. 2106/JBJS.18.01112.

51. Wahl TS, Goss LE, Morris MS, Gullick AA, Richman JS, Kennedy GD, Cannon JA, Vickers SM, Knight SJ, Simmons JW, Chu DI. Enhanced recovery after surgery (ERAS) eliminates racial disparities in postoperative length of stay after colorectal surgery. Ann Surg. 2018;268(6):1026-35. https://doi.org/10.1097/SLA. 0000000000002307.

Publisher's Note Springer Nature remains neutral with regard to jurisdictional claims in published maps and institutional affiliations. 